\title{
Role of elevated plasma soluble ICAM-1 and bronchial lavage fluid IL-8 levels as markers of chronic lung disease in premature infants
}

\author{
Sally Little, Taraneh Dean, Sheila Bevin, Michael Hall, Mark Ashton, Martin Church, \\ John Warner, Janis Shute
}

\begin{abstract}
Background - Pulmonary neutrophilia characterises both the relatively transient inflammation associated with infant respiratory distress syndrome (IRDS) and the persistent inflammation of chronic lung disease. The possibility that persistently raised markers of inflammation indicate the development of chronic lung disease in low birth weight $(<1730 \mathrm{~g})$ preterm ( $<31$ weeks) infants was therefore investigated.
\end{abstract}

Methods - Soluble ICAM-1 (sICAM-1) levels in plasma, and interleukin (IL)-8 and myeloperoxidase (MPO) levels in bronchial lavage fluid (BLF) obtained from 17 infants on days 1,5 , and 14 following birth were measured and correlations with the number of neutrophils in BLF sought. Peripheral neutrophils were isolated on Polymorphoprep and chemotactic responsiveness to IL-8 was assessed using micro Boyden chambers. Results - Sixteen infants developed IRDS and, of these, 10 infants subsequently developed chronic lung disease. Levels of IL8 in BLF at 14 days of age correlated with the long term requirement for intermittent positive pressure ventilation (IPPV). Interleukin 8 levels in BLF correlated with neutrophil numbers and MPO concentration, suggesting both recruitment and activation in response to this cytokine. Antibody depletion studies showed that approximately $50 \%$ of total neutrophil chemotactic activity in BLF was due to IL8. No difference in peripheral neutrophil chemotactic responsiveness at any age was observed for infants with IRDS or chronic lung disease. Plasma soluble intercellular adhesion molecule (sICAM-1) was higher at 14 days of age in infants who developed chronic lung disease than in those with resolving IRDS, and correlated with severity of disease, as indicated by duration of IPPV.

Conclusions - The results indicate that high levels of plasma SICAM-1 and IL-8 in BLF at day 14 correlate with the development of chronic lung disease and indicate the severity of disease.

(Thorax 1995;50:1073-1079)

Keywords: chronic lung disease, interleukin 8 , soluble intercellular adhesion molecule 1 .
Chronic lung disease of the premature neonate is defined as oxygen dependency for 28 days, together with an abnormal chest radiograph. ${ }^{1-3}$ This condition sometimes develops as a result of exposure to supplemental oxygen and positive pressure ventilation used to treat the respiratory failure of infant respiratory distress syndrome (IRDS) in premature neonates with surfactant deficiency. ${ }^{1-3}$ Neutrophil accumulation in bronchoalveolar lavage fluid characterises the pulmonary inflammation associated with both diseases. ${ }^{45}$ However, the inflammatory processes in IRDS are self-limiting, and the raised number of neutrophils seen in bronchoalveolar lavage fluid at 2-4 days of age resolve completely within one week of birth. ${ }^{5}$ Conversely, neutrophil counts remain high for at least five weeks in chronic lung disease. ${ }^{5}$ Neutrophils are active participants in the inflammatory process and not innocent bystanders as evidenced by parallel changes in neutrophil elastase activity in bronchoalveolar lavage fluid. ${ }^{45} \mathrm{~A}$ functional role for neutrophils in lung damage associated with ventilation has also been demonstrated in an animal model where granulocyte depleted animals failed to develop lung disease after surfactant deficient respiratory distress. ${ }^{6}$

Recruitment of neutrophils from the circulation occurs in four main stages: ${ }^{78}(1)$ primary adhesion events or "rolling" of neutrophils on capillary endothelium mediated by neutrophil selectins; (2) chemoattractant-dependent activation of adhesion receptors (integrins) on neutrophils; (3) stable attachment mediated by neutrophil integrin binding to endothelial intercellular adhesion molecules (ICAM-1 and ICAM-2); and (4) diapedesis leading to localisation of neutrophils in the tissue matrix. Directed migration occurs under the influence of local concentration gradients of chemoattractants in tissues. Several neutrophil chemoattractants have been described, including the relatively short-lived lipid mediators leukotriene (LT) $\mathrm{B}_{4}$, platelet activating factor (PAF), and 5-hydroxy eicosatetranoic acid (5-HETE), and mediators such as activated complement (C5a), formylpeptides, and members of the chemokine family including IL-8. Some of these - for example, C5a, $\mathrm{LTB}_{4}$ and IL-8 - have been detected in sputum and/or lavage fluid of patients with a number of diseases characterised by a neutrophilic infiltration of the lungs such as cystic fibrosis, ${ }^{910}$ ARDS, ${ }^{11}{ }^{12}$ and 
Table 1 Clinical parameters of patients in the study

\begin{tabular}{|c|c|c|c|c|c|c|c|c|c|}
\hline $\begin{array}{l}\text { Patient } \\
\text { no. }\end{array}$ & $\begin{array}{l}\text { Birth } \\
\text { weight (g) }\end{array}$ & $\begin{array}{l}\text { Gestational } \\
\text { age (weeks) }\end{array}$ & $\begin{array}{l}\text { Antenatal } \\
\text { steroid }\end{array}$ & IRDS & Exosurf & $\begin{array}{l}\text { IPPV } \\
\text { (days) }\end{array}$ & $\begin{array}{l}\text { Days in } \\
\mathrm{O}_{2}\end{array}$ & $C L D$ & $\begin{array}{l}\text { Postnatal } \\
\text { steroid }\end{array}$ \\
\hline 1 & 1100 & 30 & No & Yes & Yes & 2 & 4 & No & None \\
\hline 2 & 1040 & 28 & $3 \mathrm{~h}$ & Yes & Yes & 5 & 9 & No & None \\
\hline 3 & 1300 & 28 & $3 \mathrm{~h}$ & Yes & Yes & 4 & 7 & No & None \\
\hline 4 & 1260 & 28 & $3 \mathrm{~h}$ & Yes & Yes & 4 & 71 & Yes & None \\
\hline 5 & 1120 & 28 & $8 \mathrm{~h}$ & Yes & Yes & 15 & 56 & Yes & None \\
\hline 6 & 940 & 26 & No & Yes & Yes & 28 & 82 & Yes & 4 wks \\
\hline 7 & 1320 & 28 & No & Yes & Yes & 16 & 105 & Yes & 8 wks \\
\hline 8 & 970 & 28 & No & Yes & Yes & 8 & 112 & Yes & None \\
\hline 9 & 1620 & 30 & 3 days & No & No & 0 & 0 & No & None \\
\hline 10 & 1340 & 30 & $6 \mathrm{wks}$ & Yes & No & 0 & 5 & No & None \\
\hline 11 & 1200 & 30 & $6 \mathrm{wks}$ & Yes & No & 1 & 168 & Yes & None \\
\hline 12 & 1730 & 31 & $1 \mathrm{~h}$ & Yes & No & 1 & 4 & No & None \\
\hline 13 & 1270 & 29 & $3 \mathrm{~h}$ & Yes & Yes & 9 & 150 & Yes & $\begin{array}{r}8 \text { wks } \\
16 \text { wks }\end{array}$ \\
\hline 14 & 1660 & 30 & $\begin{array}{r}6 \mathrm{~h} \\
18 \mathrm{~h}\end{array}$ & Yes & Yes & 4 & 5 & No & None \\
\hline 15 & 780 & 26 & None & Yes & Yes & 28 & 41 & Yes & None \\
\hline 16 & 750 & 26 & None & Yes & Yes & 30 & 36 & Yes & None \\
\hline 17 & 820 & 24 & None & Yes & Yes & 64 & 64 & Yes & $2 \mathrm{wks}$ \\
\hline
\end{tabular}

IRDS $=$ infant respiratory distress syndrome; $C L D=$ chronic lung disease; Exosurf $=$ synthetic surfactant.

bacterial pneumonia. ${ }^{1213}$ Furthermore, increased levels of $\mathrm{LTB}_{4}$, 5-HETE, PAF, ${ }^{14} 15$ $\mathrm{C} 5 \mathrm{a},{ }^{15}$ and IL- ${ }^{1516}$ have been found in the tracheal aspirates of infants with chronic lung disease. However, chemotaxis of peripheral neutrophils ${ }^{17-19}$ and expression of L-selectin and the integrin MAC-1, a counter-receptor for ICAM-1, was decreased in term and preterm neonates compared with adults. ${ }^{19-21}$

Neutrophil migration across endothelial and epithelial cell barriers is dependent on the adhesion receptor ICAM-1, a molecule extensively upregulated in inflammatory disorders. ${ }^{22}$ Shedding of cell associated ICAM-1 can be induced by inflammatory cytokines ${ }^{23}$ and detection of a soluble form of ICAM- 1 in the circulation ${ }^{24}$ has been proposed to be a useful marker of inflammation. ${ }^{25}$ Thus, raised levels of sICAM-1 have been detected in serum samples from patients with a number of inflammatory disorders ${ }^{26}$ including bronchial asthma. ${ }^{27}$ Increased levels of leucocyte-derived L-selectin and endothelial-derived E-selectin in the circulation have similarly been described in systemic inflammation, although organspecific inflammation did not correlate with increased concentrations of these adhesion molecules in the circulation. ${ }^{26}$

We therefore investigated bronchial lavage fluid (BLF) levels of IL-8 and serum levels of sICAM-1 as potential markers of the progression of the acute inflammation of IRDS to the chronic phase associated with chronic lung disease. We also compared the IL- 8 induced chemotactic responsiveness of peripheral neutrophils from patients with IRDS and those with chronic lung disease.

\section{Methods}

PATIENTS

Seventeen infants (26-31 weeks gestation, birth weight $940-1730 \mathrm{~g}$ ) were consecutively recruited during a five month study which was approved by the local ethical committee. During the study period one infant was not recruited due to the presence of congenital abnormalities. Informed written consent was obtained from both parents at the time of birth, or as soon as possible thereafter. Without parental consent on day 1 , five infants were entered into the study on day 5 and three on day 14. Details of the patients and maternal steroid or infant surfactant therapy are shown in table 1 .

\section{STUDY DESIGN}

Venous blood (1-2 ml) was obtained on days 1,5 , and 14 and collected into tubes containing EDTA. Bronchial lavage was performed on day 1, 2-4 hours after birth, prior to surfactant administration (Exosurf, an artificial surfactant, $2 \times 5 \mathrm{ml} / \mathrm{kg}$ ), and on days 5 and 14 on those infants who were intubated for intermittent positive pressure ventilation (IPPV) and for whom there were no contraindications. Bronchial lavage was carried out while the infants were supine, with the head turned to the left, and two aliquots $(1 \mathrm{ml} / \mathrm{kg}$ ) of normal saline were introduced via a 5 gauge catheter. Lavage samples were aspirated immediately after each aliquot. In most cases the ventilator circuit was not broken.

The total cell count of BLF was performed on fresh lavage fluid using Kimura stain in a haemocytometer. Differential cell counts were carried out on cytospin slide preparations fixed in methanol and stained with Haema-Gurr differential stain (BDH Ltd, Poole, Dorset, UK). The remaining BLF was centrifuged at $200 \mathrm{~g}$ for 10 minutes and the supernatant was frozen in $100 \mu \mathrm{l}$ aliquots at $-80^{\circ} \mathrm{C}$.

Chronic lung disease was diagnosed if the infant received IPPV, had persisting oxygen requirement on day 28 , and had an abnormal chest radiograph. ${ }^{1}$

\section{$B L F$ dilution factor}

The dilution of the epithelial lining fluid by lavage medium was calculated as the ratio of urea concentration in the BLF to urea concentration in the plasma, ${ }^{28}$ which was measured using an in-house urease-based assay. Concentrations of IL-8 and MPO in BLF and neutrophil numbers were adjusted using this ratio. 


\section{IL-8 assay}

Interleukin 8 was measured by an ELISA which is specific for detection of free IL-8, and does not measure IL-8 in immune complexes. ${ }^{29}$ Mouse monoclonal and goat polyclonal antibodies were kindly donated by Dr Ivan Lindley, Sandoz, Vienna, and used as previously described. ${ }^{10}$ Assays were carried out on neat BLF or plasma diluted 1 in 2 with PBS/ $0.05 \%$ Tween 20.

\section{Neutralisation of IL-8 in BLF}

Neutralisation of IL-8 in BLF was achieved by incubation of BLF with goat polyclonal antiIL-8 antibody at $1 \mu \mathrm{g} / \mathrm{ml}$ for one hour at $4^{\circ} \mathrm{C}$. Bronchial lavage fluid was subsequently centrifuged (one minute at maximum speed in a microfuge) before assay for neutrophil chemotactic activity. In order to demonstrate the specificity of the neutralising antibody, human recombinant (hr) IL-8 and fMLP were treated with the antibody as for BLF, prior to their use in chemotaxis assays.

Plasma sICAM-1 assay

Soluble ICAM-1 was measured in plasma diluted 1 in 5 using a commercially available ELISA, following the manufacturer's instructions (British Biotechnology Ltd, Abingdon, UK).

\section{Myeloperoxidase assay}

Myeloperoxidase (MPO) in neat BLF was assayed by radioimmunoassay (Kabi Pharmacia, Milton Keynes, UK).

Isolation of neutrophils and plasma preparation Neutrophils were isolated to $75-95 \%$ purity by centrifugation $(400 \mathrm{~g} \times 30$ minutes) of whole blood over Polymorphoprep (Nycomed Pharma AS, Oslo, Norway). The upper plasma layer was stored in $100 \mu \mathrm{l}$ aliquots at $-80^{\circ} \mathrm{C}$. Erythrocytes in the cell pellet were removed by hypotonic lysis in $0.2 \% \mathrm{NaCl}$ for 15 seconds. Isotonicity was restored with an equal volume of $1.6 \% \mathrm{NaCl}$. Purified cells were kept on ice in Hank's buffered salt solution (HBSS) with phenol red (Gibco, Paisley, UK).

\section{Chemotaxis assays}

Chemotaxis assays were performed in duplicate using 48-well microBoyden chambers (Neuro Probe, Maryland, USA) with $5 \mu \mathrm{m}$ pore size polyvinylpyrrolidone free polycarbonate filters (Costar, High Wycombe, UK). hr IL-8 (25 $\mu \mathrm{l}$, $0.004-1.0 \mu \mathrm{g} / \mathrm{ml}$ ) or dilution buffer alone (HBSS with phenol red) was added to the lower chamber in duplicate, and isolated neutrophils $\left(50 \mu \mathrm{l}, 1 \times 10^{6} / \mathrm{ml}\right)$ were placed in the upper chamber and incubated for one hour at $37^{\circ} \mathrm{C}$. Non-migrating cells on the upper surface of the filter were removed by scraping and washing the filters. Migrated cells on the lower surface were fixed with methanol and stained (HaemaGurr stain) for counting. Five fields of view at
$600 \times$ magnification were counted. The neutrophil response was expressed as the average number of cells counted per high power field (hpf) after the value for the buffer control was subtracted. The $\mathrm{ED}_{50}$ was calculated from the dose-response curve as the concentration of IL-8 giving $50 \%$ of the maximum response.

\section{DATA ANALYSIS}

Correlations were made using Spearman's two tailed rank correlation. Differences between the patient groups were determined using the two tailed Mann-Whitney $U$ test. The effect of maternal antenatal steroid treatment and of Exosurf treatment in the infants on the development of disease was analysed using logistic regression analysis by the Medical Statistics Department at Southampton General Hospital.

\section{Results}

PATIENTS

The clinical details of the 17 infants recruited to the study are shown in table 1 . Sixteen developed RDS, and one had a systemic infection with $\beta$ haemolytic streptococcus group B. Six of the infants with RDS had an uneventful course, being extubated in air between days 4 and 9 and in whom, therefore, bronchial lavage was not subsequently performed. Ten developed chronic lung disease using the definition of Northway et al. ${ }^{1}$ Logistic regression analysis revealed that neither variation in maternal antenatal steroid treatment nor treatment with Exosurf were significant predictors of chronic lung disease. The antenatal steroids odds ratio $=0 \cdot 17(95 \%$ CI 0.01 to $2 \cdot 37), \mathrm{p}=$ $\mathrm{NS}$, and the Exosurf odds ratio $=3.0$ (95\% CI $0 \cdot 2$ to 48$), p=N S$.

\section{IL-8 IN BLF}

The IL-8 concentration in BLF samples obtained on days 1,5 , and 14 are shown in fig 1 . The number of data points reflects the number of infants still intubated for IPPV at each time point and from whom, therefore,

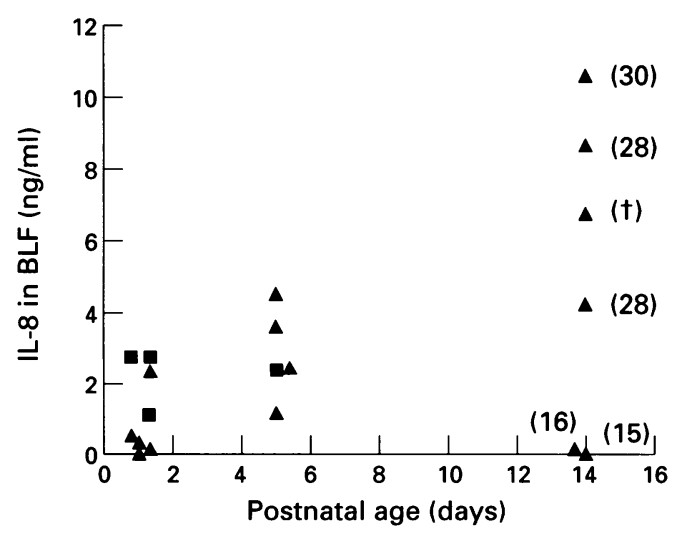

Figure 1 IL-8 concentration in bronchial lavage fluid $(B L F)$ in premature babies with IRDS (U) and chronic lung disease $(\boldsymbol{\Delta})$. Numbers in brackets indicate duration of IPPV in days. † indicates the patient died at 64 days of age following IPPV. 

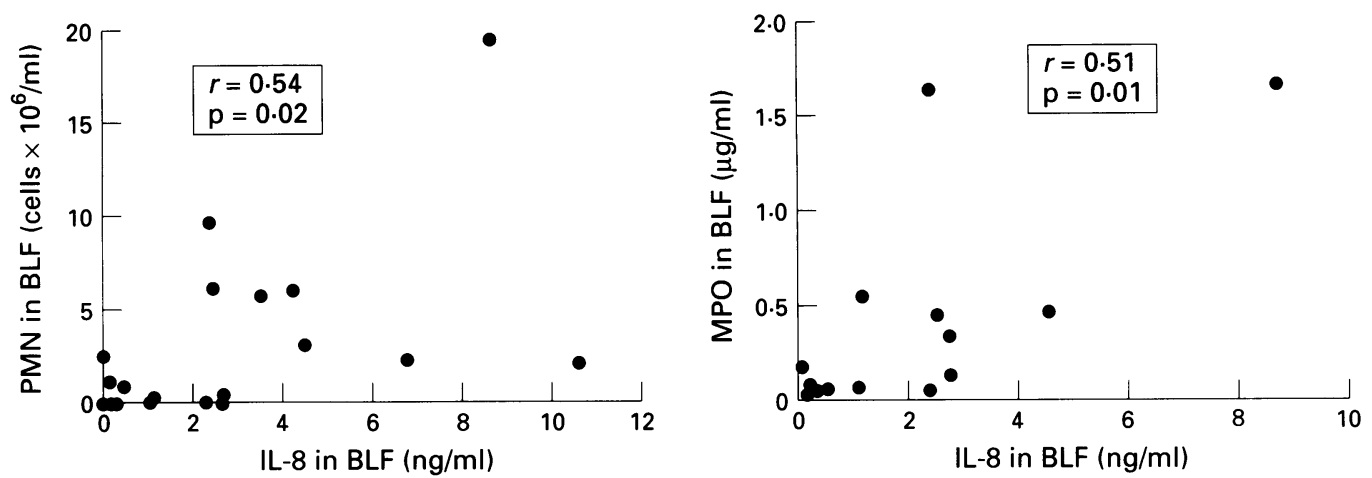

Figure 2 Correlation of IL-8 concentration in bronchial lavage fluid (BLF) with neutrophil number (PMN) and MPO activity.

BLF could be obtained for analysis. No significant difference was detected in the samples obtained on day 1 between infants who subsequently developed chronic lung disease (median $305 \mathrm{pg} / \mathrm{ml}$, range $0-2340 \mathrm{pg} / \mathrm{ml}$ ) and those in whom RDS resolved (median $2717 \mathrm{pg} / \mathrm{ml}$, range $1066-2738 \mathrm{pg} / \mathrm{ml}$ ). All of the infants sampled on day 5 were also sampled on day 1 , and IL-8 concentrations were significantly $(\mathrm{p}=$ $<0.05)$ higher than on day 1 . In addition, there was a significant $(p<0.05)$ correlation of IL-8 concentration with postnatal age in infants who developed chronic lung disease. It was also evident that at 14 days of age the IL-8 concentration in BLF (median $5519 \mathrm{pg} / \mathrm{ml}$, range 41-10615 pg/ml) was significantly correlated $(p<0.05)$ with the duration of IPPV (day of extubation indicated in brackets).

The concentrations of free IL-8 measured in BLF samples correlated significantly with both the number of neutrophils and the MPO concentration in BLF (fig 2).

The neutrophil chemotactic activity of five BLF samples from patients with chronic lung disease was assayed using adult neutrophils and was compared with the response to an optimal concentration of IL-8 (fig 3). The neutrophil chemotactic activity of BLF (26.8-52.7 neutrophils/hpf) was greater than that observed with $62.5 \mathrm{ng} / \mathrm{ml} \mathrm{IL-8} \mathrm{(16} \mathrm{neutrophils/hpf)} \mathrm{(fig}$ 4). The highest IL- 8 concentration measured in the BLF used was $1.6 \mathrm{ng} / \mathrm{ml}$, indicating that neutrophil chemoattractants other than IL-8 were present in BLF. This was tested by treating the samples of BLF with a neutralising IL-8

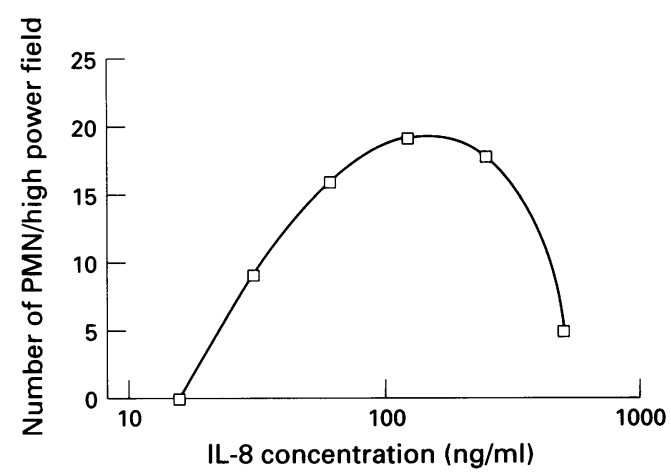

Figure 3 IL-8 dose-response curve. Neutrophils (PMN) from a single donor were used to demonstrate the migratory response of neutrophils to hr IL-8 in Boyden chambers. antibody. Antibody treatment almost completely blocked $(85 \%)$ the chemotactic response to IL-8. The specificity of the antibody was demonstrated using fMLP as chemoattractant, for which no inhibition of neutrophil chemotactic activity was observed following antibody treatment. The neutrophil chemotactic activity of BLF was inhibited by $52 \%$ (SE $5 \cdot 8 \%$ ) by the treatment with IL- 8 antibody.

\section{IL-8 IN PLASMA}

The peripheral plasma concentration of IL-8 of all the infants in the study remained below $120 \mathrm{pg} / \mathrm{ml}$. There was no trend with postnatal age and no difference between infants with IRDS or chronic lung disease.

\section{SOLUBLE ICAM-1 IN PLASMA}

Soluble ICAM-1 concentration in plasma increased in all patients between days 1 and 5 . In the group with chronic lung disease there was a highly significant $(p<0.001)$ trend of increasing concentration with postnatal age (fig 5). Additionally, at 14 days of age, levels of sICAM-1 in the plasma of patients with chronic lung disease was significantly $(p=0.02)$ higher than in the group with IRDS. For all patients,

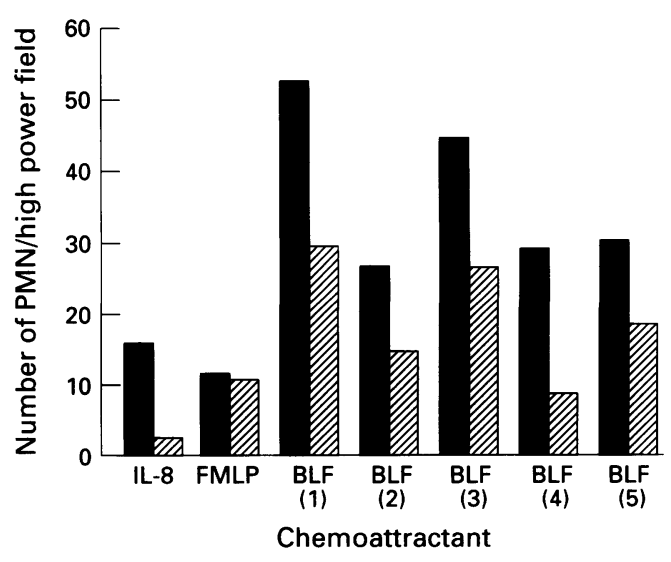

Figure 4 Effect of a neutralising IL-8 antibody on the total neutrophil (PMN) chemotactic activity of bronchial lavage fluid (BLF), assayed using neutrophils from a single donor. Bars indicate response to $I L-8(62.5 \mathrm{ng} / \mathrm{ml})$, fMLP $\left(10^{-7} M\right)$, and $B L F$ samples $(n=5)$ before (solid) and after (hatched) treatment of chemoattractants with an IL-8 neutralising antibody. 


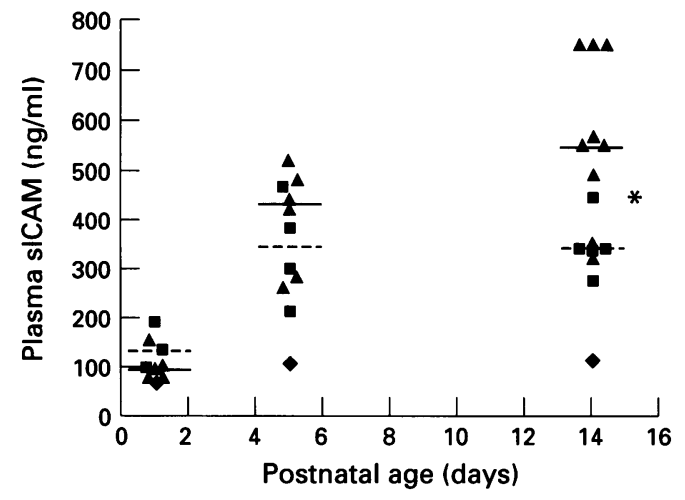

Figure 5 Plasma sICAM concentration as a function of postnatal age in premature babies with IRDS (

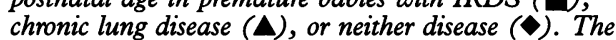
dotted and solid lines indicate the median value for the IRDS and the chronic lung disease groups, respectively. ${ }^{*} p=0.02$ difference between the patient groups.

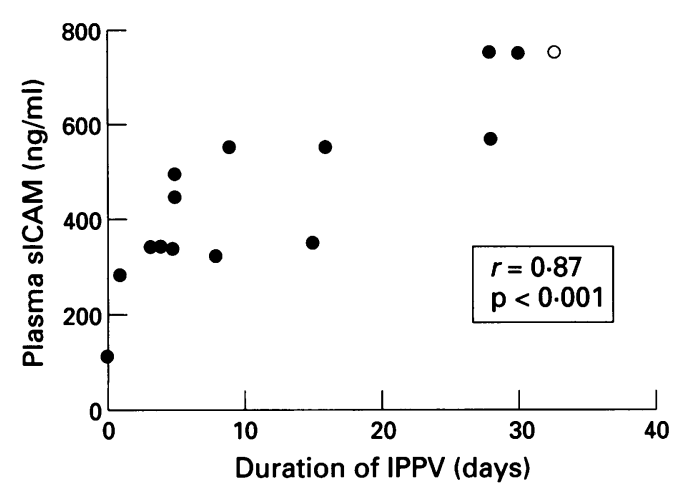

Figure 6 Correlation of plasma sICAM concentration with duration of IPPV. The open symbol indicates the patient who died.

at all ages, sICAM-1 concentrations in plasma correlated highly significantly $(p=0.005)$ with the number of neutrophils in BLF. Also, plasma sICAM-1 concentrations at 14 days of age correlated with the severity of disease as reflected by the duration of IPPV (fig 6). In the IRDS group the raised sICAM levels at five days of age did not significantly increase further. The infant who did not require ventilation maintained the lowest level of SICAM in plasma throughout the study.

PERIPHERAL NEUTROPHIL FUNCTION EX VIVO Neonatal peripheral neutrophil chemotactic responsiveness to IL-8 was determined in preliminary experiments to be maximal at an IL8 concentration of $0.5 \mu \mathrm{g} / \mathrm{ml}(6 \mathrm{nM})$. At this concentration of IL-8 there was no significant

Table 2 Peripheral neutrophil IL-8 induced chemotactic responsiveness

\begin{tabular}{lclll}
\hline Patient group & Postnatal age (days) & $n$ & Neutrophils/hpf & $E D_{s o}(\mu g / m l)$ \\
\hline IRDS & 1 & 3 & $46 \cdot 1(14 \cdot 6-88 \cdot 2)$ & $0 \cdot 11(0 \cdot 09-0 \cdot 20)$ \\
& 5 & 5 & $11 \cdot 4(4 \cdot 6-42 \cdot 4)$ & $0 \cdot 18(0 \cdot 02-0 \cdot 50)$ \\
CLD & 14 & 4 & $20 \cdot 9(9 \cdot 1-49 \cdot 7)$ & $0.06(0 \cdot 04-0 \cdot 20)$ \\
& 1 & 5 & $37(15 \cdot 3-73 \cdot 8)$ & $0.04(0 \cdot 03-0 \cdot 18)$ \\
& 5 & 6 & $10 \cdot 4(8 \cdot 2-19 \cdot 2)$ & $0 \cdot 1(0 \cdot 02-0 \cdot 55)$ \\
& 14 & 6 & $13 \cdot 2(0-70 \cdot 6)$ & $0.9(0 \cdot 11-0 \cdot 9)$ \\
\hline
\end{tabular}

IRDS $=$ infant respiratory distress syndrome; $\mathrm{CLD}=$ chronic lung disease.

Values are expressed as median (range). difference in the magnitude of the response by neutrophils from infants with IRDS or chronic lung disease (table 2), neither was a difference observed in $\mathrm{ED}_{50}$ for neutrophils from each group of patients.

\section{Discussion}

Interleukin 8 has been proposed as the major neutrophil chemoattractant in human lung ${ }^{30}$ and has been associated with a number of inflammatory conditions in adults. ${ }^{10-12}$ Recent studies have indicated relatively high concentrations of IL- 8 in the pulmonary lavage fluids of premature infants who develop chronic lung disease, ranging from $41.7 \mathrm{ng} / \mathrm{ml}$ on day 1 (22 hours after birth), ${ }^{14}$ to $11.9 \mathrm{ng} / \mathrm{ml}$ at 37 days of age. ${ }^{31}$ Others have reported up to approximately $500 \mathrm{pg} / \mu \mathrm{g}$ secretory component at 15 days of age. ${ }^{15}$ These studies did not, however, correlate IL-8 levels in lavage fluids with numbers of neutrophils nor with indices of neutrophil activation such as MPO or elastase activity in lavage fluid. Elastase and MPO activity were previously shown to be increased in chronic lung disease compared with IRDS, but no correlation with IL-8 concentrations was made. $^{32}$

We measured lower levels of IL-8 in BLF than previously reported, ${ }^{1631}$ which probably reflects the specificity of our ELISA reagents for free IL-8, and also the fact that many factors present in BLF (such as immunoglobulins, $\alpha_{2}-$ macroglobulin, secretory component, heparan sulphate and hyaluronic acid) reduce detectable IL-8 (unpublished data). Assay of uncomplexed IL-8 is relevant since this is an active form of the soluble cytokine, while complexation with IgG autoantibodies, for example, renders the ligand unable to bind to its receptor on neutrophils. ${ }^{29}$ However, not all complexing molecules inhibit IL-8 activity for example, heparan sulphate enhances the neutrophil response. ${ }^{33}$ Additionally, we found that although secretory IgA reduced detectable IL- 8 by $85 \%$, no IgA-induced inhibition of the neutrophil response to IL-8 could be demonstrated (results not shown). We have previously detected IL-8 autoantibodies of both the IgG and IgA class in bronchoalveolar lavage fluid from adults, ${ }^{34}$ and it is conceivable that immunoglobulins regulate levels of free IL-8 and thus IL- 8 bioactivity in the immature lung.

Levels of free IL-8 correlated overall with both neutrophil numbers and MPO concentration in BLF. While not excluding a role for other neutrophil activators in BLF, a role for IL-8 in both recruitment and activation of neutrophils in the inflammation associated with hyperoxia and barotrauma is suggested. This is supported by the observations that IL-8 production is increased by hyperoxia, ${ }^{35}$ reactive oxygen metabolites, ${ }^{36}$ and trauma. ${ }^{11}$ Considering the data obtained at the earliest time point, which was up to four hours after birth, we found no correlation of IL-8 levels with numbers of neutrophils or MPO concentration, nor significant differences between infants who developed IRDS and those who developed chronic lung disease. Others have suggested 
that measurement of elevated IL-8 concentrations 22 hours after birth is a good predictor of chronic lung disease in premature infants. ${ }^{15}$ However, at the four hour time point used in our study, the lack of correlation of IL8 with other markers of inflammation indicated, firstly, the lack of an inflammatory response at this time point ${ }^{5}$ and, secondly, that IL-8 in BLF may be derived by aspiration of amniotic fluid and therefore of maternal origin. ${ }^{3738}$

Interleukin 8 is not, however, the only neutrophil chemoattractant in bronchial lavage fluid and the magnitude of the IL-8 dependent chemotactic response to BLF, compared with $\mathrm{hr}$ IL-8 alone, indicates either active IL-8 complexes and/or a synergistic interaction between IL-8 and other neutrophil chemoattractants or activators in BLF. Chemotactic activity that was not inhibited by an IL-8 neutralising antibody may reflect PAF, $\mathrm{LTB}_{4}$, or 5-HETE activity, previously shown to be present in tracheal aspirates of patients with chronic lung disease, ${ }^{14}$ or other neutrophil chemoattractants such as C5a or ENA-78, a chemokine produced by bronchial epithelial cells. ${ }^{39}$ Although $\mathrm{LTB}_{4}$ was proposed by Groneck et $a l^{40}$ to be an important neutrophil chemoattractant in the early stages of chronic lung disease, they observed that late treatment of premature infants at day 16 with dexamethasone resulted in a decrease in neutrophil accumulation in pulmonary fluid which did not correlate with a decrease in $\mathrm{LTB}_{4}$ levels. The decreased neutrophil chemotactic activity of pulmonary effluent $^{40}$ may, however, be related to the significant decrease in IL-8 levels observed following dexamethasone treatment. ${ }^{31}$ The cellular source of IL-8 in BLF is unknown, but may be derived from bronchial epithelial cells, ${ }^{41}$ alveolar macrophages, ${ }^{42}$ or pulmonary fibroblasts. ${ }^{43}$ Interleukin 8 synthesis by these cells is upregulated by the proinflammatory cytokines IL-1 $\beta$ and TNF- $\alpha$ and inhibited by dexamethasone. The cytokines IL-1 $\beta^{4044}$ and TNF- $\alpha^{45}$ were present in bronchial aspirates of preterm infants at low concentrations at birth which increased at day 4 in parallel with other inflammatory processes. Higher concentrations occurred in infants requiring oxygen for a long time, ${ }^{45}$ and levels of IL- $1 \beta$ and TNF- $\alpha$ were reduced by dexamethasone therapy. ${ }^{4045}$ These observations support our finding that IL-8 in BLF appears to be a marker of disease progression. In addition to the importance of established cytokine networks in the control of pulmonary IL-8 production, ${ }^{46}$ increasing neutrophil elastase levels ${ }^{45}$ may play a part in amplification of IL-8 production by bronchial epithelial cells ${ }^{47}$ as inflammation progresses to the chronic phase.

ICAM-1 expression is upregulated by inflammatory cytokines ${ }^{22}$ and is abundant in bronchial endothelium and epithelium. ${ }^{4849}$ In an animal model, hyperoxia induced increased expression of ICAM-1 on alveolar epithelium. ${ }^{5051}$ Additionally, raised levels of sICAM in tracheal aspirates of infants with chronic lung disease were suggested to be a consequence of lung injury. ${ }^{52}$ Levels of sICAM-1 in serum are diagnostic for various inflammatory and immune disorders, ${ }^{2526}$ and our results indicate that plasma sICAM-1 levels may also be diagnostic for the development of chronic lung disease. Higher levels of plasma sICAM-1 in infants with chronic lung disease than in those with IRDS were significantly correlated with the severity of disease, as determined by the subsequent IPPV requirement. A significant increase in plasma sICAM-1 levels was observed on day 5 in infants with IRDS and chronic lung disease. Those with IRDS, in whom inflammation resolved, showed no further increase in this parameter. Only in those with chronic lung disease was a significant increase in plasma sICAM observed at day 14 . Thus, sICAM-1 in plasma may reflect endothelial damage at sites of inflammation, particularly in infants with chronic lung disease where persistent neutrophil infiltration of the lungs appears to be mediated by sustained elevated levels of IL-8. The lack of difference in neutrophil chemotactic response to IL-8 indicated that this neutrophil function was not responsible for differences in the course of inflammation in the patient groups. Our experiments did not, however, take into account the possible differential expression of adhesion molecules or other functions in neutrophils from the two groups. Thus, we propose that increased levels of IL-8 in BLF and SICAM-1 in plasma mark the progress of IRDS to chronic lung disease. Factors which may be important in the regulation of inflammation in IRDS include alpha-1 protease inhibitor ${ }^{45}$ and IL-1 $\beta$ receptor antagonists. ${ }^{44}$ In view of the importance of IL-8 in the development of chronic lung disease, we propose that IL-8 autoantibodies in BLF may be important regulators of the activity of this cytokine and this is the subject of our current research.

This study was supported by a grant from the Wessex Medical Trust, UK.

1 Northway WH, Rosan RC, Porter DY. Pulmonary disease following respirator therapy of hyaline membrane disease: bronchopulmonary dysplasia. $N$ Engl $f$ Med 1967;276: bronchop

2 Philip AGS. Oxygen plus pressure plus time: the etiology of bronchopulmonary displasia. Pediatrics 1975;55:44-50.

3 Robertson B. The evolution of neonatal respiratory distress syndrome into chronic lung disease. Eur Respir f 1989;2 33-37S.

4 Merritt TA, Cochrane CG, Holcomb K, Bohl B, Hallman $\mathrm{M}$, Strayer D, et al. Elastase and alpha 1-proteinase inhibitor activity in tracheal aspirates during respiratory distress syndrome. Role of inflammation in the pathogenesis of bronchopulmonary dysplasia. F Clin Invest 1983 72:656-66.

5 Ogden BE, Murphy SA, Saunders GC, Pathak D, Johnson JD. Neonatal lung neutrophils and elastase/proteinase inhibitor inbalance. Am Rev Respir Dis 1984;130:817-21.

6 Kawano T, Mori S, Cybulsky M, Burger R, Ballin A, Cutz $\mathrm{E}$, et al. Effect of granulocyte depletion in a ventilated $\mathrm{E}$, et al. Effect of granulocyte depletion in a ventilated
surfactant-depleted lung. $\mathcal{F}$ Appl Physiol 1987;62:27-33.

7 Butcher EC. Leukocyte-endothelial cell recognition: three (or more) steps to specificity and diversity. Cell 1991;67: 1033-6.

8 Strieter RM, Lukacs NW, Standiford TJ, Kunkel SL. Cytokines and lung inflammation: mechanisms of neutrophi recruitment to the lung. Thorax 1993;48:765-9.

9 Zakrzewski JT, Barnes NC, Piper PJ, Costello JF. Detection of sputum eicosanoids in cystic fibrosis and in norma saliva by bioassay and radioimmunoassay. $\mathrm{Br} f \mathrm{Clin}$ Phar macol 1987;23:19-27.

10 Dean TP, Dai Y, Shute JK, Church MK, Warner JO. IL-8 concentrations are elevated in bronchoalveolar lavage, sputum and sera of children with cystic fibrosis. Paediat Res 1993;34:159-61.

11 Donnelly SC, Strieter RM, Kunkel SL, Walz A, Robertson $\mathrm{CR}$, Carter DC, et al. Interleukin-8 and development of adult respiratory distress syndrome in at-risk patient of aduit respiratory distress syndro

12 Chollet-Martin S, Montravers P, Gibert C, Elbim C, Des- 
monts JM, Fagon JY, et al. High levels of interleukin-8 in the blood and alveolar spaces of patients with pneumonia and adult respiratory distress syndrome. Infect Immun 1993;61:4553-9.

13 Hopkins H, Stull T, von Essen SG, Robbins RA, Rennard SI. Neutrophil chemotactic factors in bacterial pneumonia. Chest 1989;95:1021-7.

14 Stenmark KR, Eyzaguirre M, Westcott JY, Henson PM, Murphy RC. Potential role of eicosanoids and PAF in the pathophysiology of bronchopulmonary dysplasia. Am Rev Respir Dis 1987;136:770-2.

15 Groneck P, Götze-Speer B, Oppermann M, Eiffert H, Speer CP. Association of pulmonary inflammation and increased microvascular permeability during the development of bronchopulmonary dysplasia: a sequential analysis of inflammatory mediators in respiratory fluids of high-risk preterm neonates. Pediatrics 1994;93:712-8.

16 McColm JR, McIntosh N. Interleukin-8 in bronchoalveolar lavage samples as predictor of chronic lung disease in premature infants. Lancet 1994;343:729.

17 Dos Santos C, Davidson D. Neutrophil chemotaxis to leukotriene $\mathrm{B}_{4}$ in vitro is decreased for the human neonate. Pediatr Res $1993 ; 33: 242-6$.

18 Kamran S, Usmani SS, Wapnir RA, Mehta R, Harper RG. In vitro effect of indomethacin on polymorphonuclea leukocyte function on preterm infants. Pediatr Res 1993 33:32-5.

19 Carr R, Pumford D, Davies JM. Neutrophil chemotaxis and adhesion in preterm babies. Arch Dis Child 1992;67:813-7.

20 Torok C, Lundahl J, Hed J, Lagercrantz H. Diversity in regulation of adhesion molecules (MAC-1 and L-selectin) in monocytes and neutrophils from neonates and adults. Arch Dis Child 1993;68:561-5.

21 Anderson DC, Abbassi O, Kishimoto TK, Koenig JM, McIntire LV, Smith CW. Diminished lectin-, epidermal growth factor-, complement binding domain-cell adhesion molecule-1 on neonatal neutrophils underlies their immolecule-1 on neonatal neutrophils underlies their im-
paired CD18-independent adhesion to endothelial cells paired CD18-independent adhesion

22 Montefort S, Holgate ST. Adhesion molecules and their role in inflammation. Respir Med 1991;85:91-9.

23 Becker JC, Dummer R, Hartman AA, Burg G, Schmidt RE. Shedding of ICAM-1 from human melanoma cell lines induced by IFN- $\gamma$ and tumor necrosis factor- $\alpha$. Functional consequences on cell-mediated cytotoxicity. $f$ Immunol 1991;147:4398-401.

24 Rothlein R, Mainolfi EA, Czajkowski M, Marlin SD. A form of circulating ICAM-1 in human serum. $\mathcal{F}$ Immunol 1991;147:3788-93.

25 Seth R, Raymond FD, Makoba MW. Circulating ICAM 1 isoforms: diagnostic prospects for inflammatory and immune disorders. Lancet 1991;338:83-4.

26 Gearing AJH, Newman W. Circulating adhesion molecules in disease. Immunol Today 1993;14:506-12.

27 Hashimoto S, Imai K, Kobayashi T, Amemiya E, Takahash $\mathrm{Y}$, Tomita, et al. Elevated levels of soluble ICAM-1 in sera from patients with bronchial asthma. Allergy 1993; 48:370-2.

28 Many TW, Merrill WW, Rankin JA, Reynolds HY. Limitations of using urea to quantify epithelial lining fluid recovered by bronchoalveolar lavage. Am Rev Respir Dis 1987;135:1276-80.

29 Sylvester I, Yoshimura T, Sticherling $M$, Schroder J-M Ceska $M$, Peichl $P$, et al. Neutrophil attractant protein-1 immunoglobulin $G$ immune complexes and free antiNAP-1 antibody in human serum. $\mathcal{F}$ Clin Invest 1992;90: 471-81.

30 Kunkel SL, Standiford T, Kasahara K, Strieter RM. Interleukin-8: the major neutrophil chemotactic factor in the lung. Exp Lung Res 1991;17:17-23.

31 Adeniyi-Jones S, Ramdial HL, McCormick M, Hyslop T, Spitzer AR. Dexamethasone (D) decreases interleukin-6 (IL-6) and interleukin-8 (IL-8) levels in tracheal lavage of infants with bronchopulmonary dysplasia (BPD) Pediatr Res 1993;33:61A.

32 Zimmerman JJ, Hariharan N, Lewandoski JR, ArqueteSiewert J. Markers of alveolar oxidant stress in respiratory distress syndrome (RDS) predict bronchopulmonary dysplasia (BPD) Pediatr Res 1993;33:350A.

33 Webb LMC, Ehrengruber MU, Clark-Lewis I, Baggiolini M Rot A. Binding to heparan sulphate or heparin enhances neutrophil responses to interleukin 8. Proc Natl Acad Sci USA 1993;90:7158-62.

34 Shute JK, Taylor IK, Shaw RJ, Spellerberg MB, Lindley I, Church MK. Autoantibodies to IL-8 in bronchoalveolar lavage fluid from normal and asthmatic individuals. Respir Med 1993;87:650-1A.

35 Metinko AP, Kunkel SL, Standiford TJ, Strieter RM. Anoxia-hyperoxia induces monocyte-derived interleukin-8. $\mathcal{J}$ Clin Invest 1992;90:791-8.

36 De Forge LE, Fantone JC, Kenney JS, Remick DG. Oxygen radical scavengers selectively inhibit interleukin-8 production in human whole blood. $\mathcal{F}$ Clin Invest 1992;90: 2123-9.

37 Arnon S, Grigg J, Silverman M. Association between pulmonary and gastric inflammatory cells on the first day of life in preterm infants. Pediatr Pulmonol 1993;16:59-61.

38 Romero R, Ceska M, Avila C, Mazor M, Behnke R, Lindley I. Neutrophil attractant/activating peptide-1/interleukin-8 interm and preterm parturition. Am $\mathcal{F}$ Obstet Gynecol 1991; 165:813-20.

39 Walz A, Burgener R, Car B, Baggiolini M, Kunkel SL, Strieter RM. Structure and neutrophil-activating properties of a novel inflammatory peptide (ENA-78) with homology to interleukin 8. F Exp Med 1991;174:1355-62.

40 Groneck P, Reuss D, Götze-Speer B, Speer CP. Effects of dexamethasone on chemotactic activity and inflammatory mediators in tracheobronchial aspirates of preterm infants at risk for chronic lung disease. $\mathcal{F}$ Paediatr 1993;122: 938-44.

41 Kwon OJ, Au BT, Collins PD, Baraniuk JN, Adcock IM, Chung KF, et al. Inhibition of interleukin-8 expression by dexamethasone in human cultured airway epithelial cells. Immunology 1994;81:389-94.

42 Standiford TJ, Kunkel SL, Rolfer MW, Evanoff HL, Allen RM, Strieter RM. Regulation of human alveolar macrophage and blood monocyte-derived interleukin-8 by phage and blood monocyte-derived interleukin-8 by prostaglandin $\mathrm{E}_{2}$ and del $1992 ; 6: 75-81$.

43 Tobler A, Meier R, Seitz M, Dewald B, Baggiolini M, Fey MF. Glucocorticoids down regulate gene expression of GM-CSF, NAP-1/IL-8 and IL-6, but not M-CSF in human fibroblasts. Blood 1992;79:45-51.

44 Hallman $M$, Bry $K$. Interleukin- $1 \beta$ and interleukin receptor antagonist in airway specimens of infants with RDS. Paediatr Res 1993;33:327A.

45 Murch SH, MacDonald TT, Wood CBS, Costeloe KI Tumour necrosis factor in the bronchoalveolar secretions of infants with respiratory distress syndrome and the effect of dexamethasone treatment. Thorax 1992;47:44-7.

46 Rolfe MW, Kunkel SL, Standiford TJ, Chensue SW, Allen $\mathrm{RM}$, Evanoff HL, et al. Pulmonary fibroblast expression of interleukin-8, a model for alveolar macrophage-derived cytokine networking. Am $\mathcal{f}$ Respir Cell Mol Biol 1991;5: 493-501.

47 Nakamura H, Yoshimura K, McElvaney NG, Crystal RG. Neutrophil elastase in respiratory epithelial lining fluid of individuals with cystic fibrosis induces interleukin- 8 gene expression in a human bronchial epithelial cell line. $\mathscr{f}$ Clin Invest 1992;89:1478-84.

48 Montefort S, Roche WR, Howarth PH, Djukanovic $R$ Gratziou C, Carroll $M$, et al. Intercellular adhesion molecule-1 (ICAM-1) and endothelial leucocyte adhesion molecule-1 (ELAM-1) expression in the bronchial mucosa of normal and asthmatic subjects. Eur Respir $¥ 1992 ; 5$ : 815-23.

49 Montefort S, Feather IH, Wilson SJ, Haskard DO, Lee TH, Holgate ST, et al. The expression of leukocyte-endothelial adhesion molecules is increased in perennial allergic rhinitis. Am $\mathcal{f}$ Respir Cell Mol Biol 1992;7:393-8.

50 Welty SE, Rivera JL, Elliston JF, Smith CV, Zeb T, Ballantyne $\mathrm{CM}$, et al. Increases in lung tissue expression of intercellular adhesion molecule- 1 are associated with hyperoxic lung injury and inflammation in mice. $A m \mathcal{F}$ Respir Cell Mol Biol 1993;9:393-400.

51 Kang B-H, Crapo JD, Wegner CD, Letts G, Chang LY. Intercellular adhesion molecule-1 expression on the alveolar epithelium and its modification by hyperoxia. $\mathrm{Am}$ Ұ Respir Cell Mol Biol 1993;9:350-5.

52 Kojima T, Sasai M Kobayashi Y Increased soluble ICAM1 in tracheal aspirates of infants with bronchopulmonary dysplasia. Lancet 1993;342:1023-4. 